\section{Care or burn in the ICU}

Burnout syndrome (BOS) is a common problem, affecting $25-60 \%$ of healthcare professionals (HCPs) working in the intensive care unit (ICU) ${ }^{[1]}$ Recently an American Critical Care Societies' collaborative statement called for action to improve the ICU working environment. ${ }^{[2]}$ The core symptoms of BOS are emotional exhaustion, depersonalisations and perceived lack of personal accomplishment. ${ }^{[2]}$ In a previous issue of this journal we published an editorial, 'Crash and burn', highlighting the problem of BOS and the closely associated condition of post-traumatic stress disorder in ICU personnel..$^{[3]}$

Several studies have identified stressful interactions with relatives as a factor that adds to the burden of this demanding workplace. The response of burnt-out doctors and nurses is to avoid or minimise contact with the relatives, particularly if they are perceived to be demanding or 'difficult'. Understanding the needs of families can help us support families and, in doing so, help ourselves. Even when we are managing the most hopeless ICU patient, job satisfaction can be achieved by knowing that we have done the best we could to help a family cope with a stressful situation.

In this issue we publish a study which used a grounded theory approach to establish the needs of the families of ICU patients. ${ }^{[4]}$ Common themes that emerged were the need for information sharing, reassurance, consolidation, resources, and cultural and religious awareness. Helping families that have been thrust into an unfamiliar and frightening situation to survive emotionally requires an understanding of the coping mechanisms relatives adopt. Establishing trust between HCPs and relatives is the first essential step. This is not achieved if discordant information is being supplied.

De Beer and Brysiewicz's study ${ }^{[4]}$ highlights the problem of contradictory information being supplied by different members of the ICU team. An earlier study ${ }^{[5]}$ conducted in French ICUs also showed that consistent information was the most important factor associated with family satisfaction.

Communication is a two-way street and involves not only informing the relatives of the patient's condition in an appropriate and compassionate way but also listening to family members and allowing them time to voice their fears and concerns. Family conferences where relatives talk more than the doctor are rated as more satisfactory by the family. ${ }^{[6]}$

The need for reassurance was another key theme that emergend from the study. This is not such a simple need to meet in the critically ill. It is our human instinct to reassure, and families are keen to grasp at any straw offered. Unfortunately, we have all seen apparently improving patients suddenly deteriorate, and the ensuing blame games that may follow. The opposite extreme, of being overly pessimistic, is also not appropriate as we should not deny the 'right to hope' as long as there is some justification for this. Perhaps the best approach is one of cautious optimism, while assuring families that everything possible is being done for their loved one.

Providing suitable facilities for families who spend long hours in the ICU is often overlooked, especially in our cash-strapped state hospitals. Minimum requirements are comfortable bedside seating, a well-furnished waiting area and a separate private room for family conferences. An explanatory brochure about the ICU and sleep-over facilities is one of the additional suggestions from the current study. ${ }^{[4]}$

We do the best we can for our patients, but in our hectic clinical lives we so often ignore the needs of families. Caring for their families is what patients want, and, in doing so, we are caring for ourselves.

\section{Lance Michell}

Editor

lance.michell@uct.co.za

1. Teixeira C, Ribeiro O, Fouseca A, Cavalho A. Burnout in intensive care units - a consideration of the possible prevalence and frequency of new risk factors: A descriptive correlational multicentre study. BMC Anesthesiol 2013;13(1):38. http://dx.doi.org/10.1186/1471-2253-13-38

2. Moss M, Good V, Gozal P, Kleinpell R, Sessler C. An official critical care societies collaborative statement - burnout syndrome in critical care health-care professionals: A call for action. Chest 2016;150(1):17-26. http://dx.doi.org/10.1016/j.chest.2016.02.649

3. Fouché N. Crash and burn. S Afr J Crit Care 2010;26(2):36-40.

4. De Beer J, Brysiewicz P. The needs of family members of intensive care patients - a grounded theory study. S Afr J Crit Care 2016;32(2):44-49. http://dx.doi.org/10. 7196.SAJCC.v32i2.298

5. Azoulay E, Pochard F, Chevret S, et al. Meeting the needs of intensive care unit families. Am J Respir Crit Care Med 2001;163(1):135-139. http://dx.doi.org/10.1164/ajrccm.163.1.2005117

6. McDonagh JR, Elliott TB, Engelberg RA, et al. Family satisfaction with family conferences about end-of-life care in the ICU: Increased proportion of family speech is associated with increased satisfaction. Crit Care Med 2004;32(7):1484-1488.

S Afr J Crit Care 2016;32(2):42. DOI:10.7196.SAJCC.v32i2.305

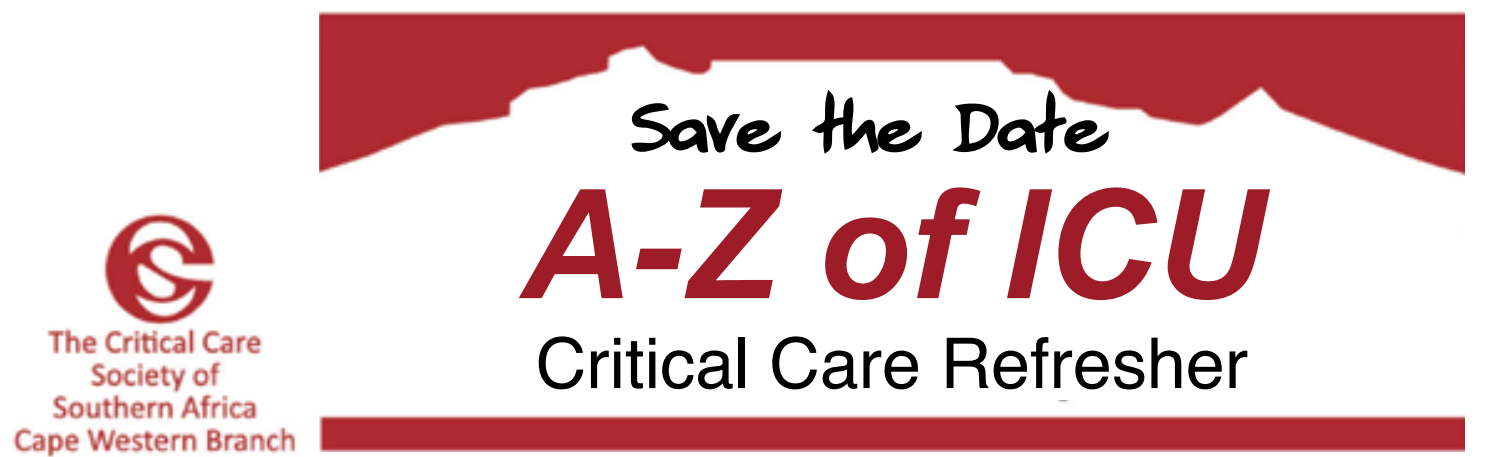

22 - 23 July 2017

Nedbank Clocktower, V\&A Waterfront, Cape Town

Enquiries: Tel: +27 217120571 or critcare2017@eventmanagementsolutions.co.za 